\title{
GERANDO VALOR NA CADEIA DE FLORES DE CORTE NO MERCADO BRASILEIRO
}

$\begin{array}{ll}\text { Recebido em: } & 11.12 .2017 \\ \text { Aprovado em: } & 18.12 .2017\end{array}$

\section{Milton Hummel}

Diretor geral da Cooperflora - Cooperativa de Floricultores. Graduado em Engenharia Agronômica pela

Unesp, tem especialização em Marketing pela ESPM.

E-mail:milton.hummel@cooperflora.com.brehummel.milton@gmail.com

\section{Lilian Aparecida P. Miguel}

Professora do Centro de Ciências Sociais e Aplicadas da Universidade Presbiteriana Mackenzie, docente permanente do Mestrado Profissional em Administração do Desenvolvimento de Negócios.

E-mail: lilian.miguel@mackenzie.br

\section{RESUMO}

O objetivo deste trabalho é relatar a proposta de um modelo de negócios, envolvendo o atendimento aos clientes de uma cooperativa de flores de corte, a partir de uma oportunidade identificada por meio da análise detalhada da cadeia de valor em que a empresa se encontra atuando no momento. Foram considerados vários elementos-chave para a análise em questão. Partindo-se das premissas de que o produto é altamente perecível, a produção é afetada pelo clima e sua sazonalidade, a comercialização se utiliza de um sistema de vendas via internet, e a venda é diária, buscou-se uma solução que gere valor baseado na 
lógica serviço-dominante, no caso, as flores de corte. O modelo proposto aqui, já em início de execução, possui em seu bojo uma oportunidade direcionada à facilitação da compra por parte do último elo da cadeia produtiva, o decorador, tendo-se em conta que tal modelo se baseia no fato de que o resultante dessa relação (empresa-decorador) será bem-sucedido dependendo fortemente da forma em quão bem cada agente usará os recursos dominados pelo outro agente, em uma relação de interdependência inequívoca.

\section{PALAVRAS-CHAVE}

Criação de valor. Mercado B2B. Mercado de flores. Cadeia de valor.

\section{INTRODUÇÃO}

O desafio de aproximar a tecnologia disponível às firmas e realizar melhorias inovadoras por meio da utilização de ferramentas de gestão faz-se presente aos gestores. Em ambientes do mercado agrícola, a utilização de equipamentos e técnicas modernas ocorre nas fazendas de forma natural, entretanto, para a operação comercial pode-se agregar valor por meio de soluções tecnológicas que trarão transparência e aumento de valor à cadeia.

Com base em tal desafio, o presente trabalho propõe uma solução na cadeia de valor da Cooperativa A, focando no atendimento a um importante elo, o decorador, baseada na lógica serviço-dominante, pelo entendimento de que por trás de todo e qualquer bem físico existe a prestação de um serviço relacionado, sendo este o que dá o real valor àquele bem físico, no caso, as flores.

Baseado na estrutura proposta por Marcondes, Miguel, Franklin e Perez (2017), este relato está estruturado da seguinte forma: na próxima seção, são apresentados o contexto e a realidade investigada. Em seguida, detalha-se o diagnóstico feito sobre a oportunidade. A 
seção que segue apresenta a criação de valor para cada um dos stakeholders envolvidos, concluindo-se, então, na última seção.

\section{CONTEXTO E REALIDADE INVESTIGADA}

\section{mercado de flores no Brasil}

No mundo, como vários produtos não essenciais, o consumo de flores e plantas or- namentais varia de acordo com a renda do país, sua conjuntura econômica, a classe social à qual o consumidor pertence, fatores de gênero e, principalmente, por influências culturais. A combinação desses fatores influencia diretamente a evolução de consumo desses produtos ao longo do tempo.

Segundo Neves e Pinto (2015), o Produto Interno Bruto (PIB) da cadeia produtiva de flores e plantas ornamentais do Brasil, em 2014, foi de R 4,51 bilhões (Tabela 1).

TABELA 1 - Estimativa do produto interno bruto da cadeia produtiva de flores e plantas ornamentais do Brasil em 2014

\begin{tabular}{|c|c|c|c|}
\hline Produto & $\begin{array}{l}\text { Mercado Interno } \\
\text { (MI) (R\$) }\end{array}$ & $\begin{array}{l}\text { Mercado Externo } \\
(M E)(R \$)\end{array}$ & Total (MI + ME) (R\$) \\
\hline Floricultura & 984.330 .709 & - & 984.330 .709 \\
\hline Decoração & 2.340 .728 .679 & - & 2.340 .728 .679 \\
\hline Paisagismo & 649.395 .492 & - & 649.395 .492 \\
\hline Autosserviço & 385.161 .923 & - & 385.161 .923 \\
\hline Atacados para o consumidor final & 120.700 .722 & - & 120.700 .722 \\
\hline Produtores para o consumidor final & 60.265 .288 & - & 60.265 .288 \\
\hline Exportação & - & 55.958 .381 & 55.958 .381 \\
\hline Importação & - & -83.004 .272 & -83.004 .272 \\
\hline Total & 4.540 .582 .813 & -27.045 .891 & 4.513 .536 .922 \\
\hline
\end{tabular}

Fonte: Adaptado de Neves e Pinto (2015). 
Para a contextualização do quão recente esse mercado é no Brasil, até a década de 1940, a produção era feita por imigrantes europeus (de origem portuguesa e italiana) para uso doméstico (visitas em cemitérios ou decoração da casa) e demanda de luxo. Nessa época, predomina uma produção amadora, sem condições ou capacidade de suprir uma demanda potencial do país (TSUBOI; TSURUSHIMA, 2009).

A partir de meados da década de 1950, ocorre o fortalecimento da capacidade produtiva devido às imigrações japonesas e holandesas, que trouxeram consigo novas tecnologias, além da criação de rodovias entre os grandes centros urbanos. Já na década de 1950, sob influência do avanço da urbanização, da industrialização e da ascensão do setor de serviços, passam a surgir a demanda profissional e a demanda pública, como dois novos segmentos consumidores, fator que resulta em aumento no consumo interno (TSUBOI; TSURUSHIMA, 2009).

Em meados da década de 1990 até o final da década de 2000, há um movimento de interiorização do consumo de flores, relacionado ao crescimento da renda da população e desenvolvimento de cidades, distantes do eixo Rio de Janeiro e São Paulo, como polos regionais, possibilitando uma demanda que não existia.

Em muito contribuiu a evolução das condições de infraestrutura em logística, tanto em relação às estradas como aos meios de transporte destinados para o envio dos produtos a esses mercados, como, por último, a melhoria genética de espécies mais adequadas para uma maior durabilidade pós-colheita (maior shelf-life).

No período de 2000 até 2014, um fator que impulsionou o aumento de consumo foi a maior disponibilidade de renda da população. Esse fator, acrescido à maior eficiência das redes varejistas quanto à qualidade do produto e disponibilidade em várias regiões do Brasil, possibilitou uma forte evolução das vendas para uso próprio. Por outro lado, o mercado de floriculturas passa a ter uma queda constante ao longo desse período, devido à forte concorrência dos varejistas alimentares.

Nesse período surgem as vendas on-line, que possuem ainda uma participação baixa em volume de vendas, mas já representativa monetariamente, devido ao valor agregado dos produtos vendidos. Nesse ínterim, de acordo com dados do Sebrae (2015), os gastos com festas e cerimoniais tiveram um crescimento de $100 \%$ nos últimos cinco anos, sendo o 
casamento o principal evento (95\% dos noivos contrataram serviços de decoração no intervalo apurado).

A partir da crise de 2014 três movimentos no mercado de flores são percebidos:

- O primeiro movimento é um consumidor optando pela compra de produtos com maior durabilidade e com baixa dificuldade de manutenção pós-compra (frequência de rega, pouca influência da incidência de luz etc.), sendo a grande vencedora a orquídea, e suas mais diversas espécies e variedades. Essa preferência está correlacionada à acentuada queda de preços de venda nos últimos anos, fator gerado pela maior disponibilidade e incremento técnico-produtivo. $\mathrm{O}$ canal de vendas que mais se apropriou desses ganhos foi o varejo alimentar.

- O segundo movimento é o consumidor optando por festas com orçamentos menores que nos anos anteriores à crise. O uso de flores passa a ter um papel menor no contexto global da festa/evento.

- O terceiro movimento é derivado do segundo, em que os decoradores passam a trabalhar com flores artificiais para reduzir os custos de decoração floral. A prática ocorre principalmente em artes florais suspensas (maior distância dos olhos e do toque) e em festas noturnas.

No Brasil, atualmente, a produção de flores e plantas ornamentais destina 97\% do total do volume financeiro comercializado pelos produtores ao mercado interno, tendo a exportação baixa significância (IBRAFLOR, 2015).

\section{A produção de flores no Brasil}

Segundo dados do Ibraflor, o Brasil apresentou em 2014 uma área plantada com flores e plantas ornamentais de aproximadamente 15.000 hectares, com 8.248 produtores se dedicando a essa atividade.

O Estado de São Paulo se destaca (Gráfico 1), tendo como regiões produtoras Holambra (composta principalmente de produtores de origem holandesa), Atibaia, Ibiúna, Mogi das Cruzes (as três compostas principalmente de produtores de origem nipônica). 


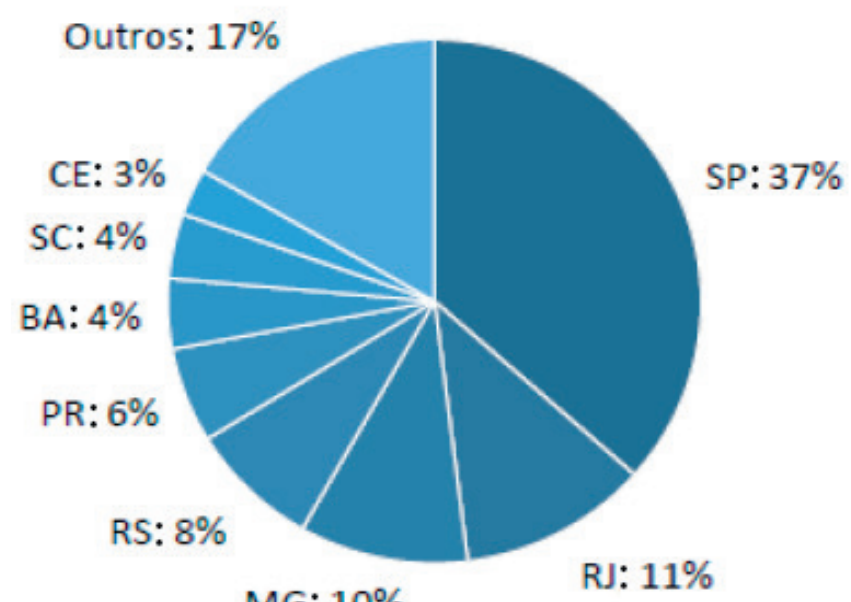

GRÁFICO 1 - Distribuição do faturamento brasileiro de flores e plantas ornamentais por Estado (2014)

Fonte: Ibraflor (2015).

Já as principais espécies de plantas são apresentadas no Quadro 1. produzidas, segundo dados do Ibraflor,

\begin{tabular}{ll}
\hline Categoria & Espécies \\
\hline \multirow{2}{*}{ Flores e folhagens de corte } & Alstroemeria, Lírio, Crisântemo, Rosa, Gérbera, Boca-de-leão, \\
& $\begin{array}{l}\text { Lisianto, Gipsófila, Cravo, Áster, Folhagem, Orquídeas, } \\
\text { Helicônia, Protea e Solidago }\end{array}$ \\
\hline \multirow{2}{*}{ Flores e plantas de vaso } & Antúrio, Lírio, Begônia, Kalanchoe, Kalanchoe Dobrado, \\
& Violeta, Denphalaen, Azaleia, Rosa, Phalaenopsis, Crisântemo \\
\hline Plantas ornamentais e paisagismo, & Forração, cactos e suculentas, Raphis, Phoenix, Cyca, \\
exceto grama & Podocarpus, Bucus, Trachycarpus e arbustos diversos \\
\hline
\end{tabular}

QUADRO 1 - Principais espécies e grupo de plantas por categoria produtiva da cadeia produtiva de flores e plantas ornamentais do Brasil (2014)

Fonte: Ibraflor (2015). 


\section{A comercialização de flores e plantas ornamentais}

O precursor para um modelo de comercialização profissional foi iniciado na década de 1970, por meio da Cooperativa Agropecuária Holambra (Caph), pela coordenação, produção e comercialização de flores. No ano de 1989, a Caph introduz o Cooperativa B, um sistema holandês de leilão. Esse modelo baseia-se em um leilão diário para a comercialização dos produtos, no qual a oferta e a procura fazem a formação do preço, referenciando todo o mercado. Com o advento da internet e de ambientes virtuais, o modelo está sendo revisto no mercado holandês, referência mundial na venda por leilão de flores e plantas ornamentais.

No ano de 1999 a Caph entra em crise, fator crítico para a origem das duas principais cooperativas do mercado brasileiro de flores atualmente:

- A Cooperativa B, fundada em 2001 pelos produtores que decidiram manter e expandir o modelo de vendas em pregão. Vale comentar que além do sistema de leilão (chamado de Klock), a Cooperativa B oferece a seus cooperados um sistema de vendas on-line, chamado de Cooperativa B Online, o sistema denominado "intermediação", que consiste na facilitação do estabelecimento de contratos de comercialização diretamente com os clientes.

- A Cooperativa A, objeto deste trabalho, surge, então, como uma dissidência da Caph e seu modelo de gestão. Um dos norteadores da cooperativa é de que os seus cooperados devem estar sempre com mais influência do que a própria cooperativa. Ou seja, a cooperativa não pode ser maior do que os cooperados, buscando ter uma menor assimetria de informações entre os cooperados.

A empresa está sediada no município de Holambra, estado de São Paulo, e foi fundada em 1999 por um grupo de produtores de flores. Atualmente, além da sede, possui três unidades de negócios, com estrutura de recepção, armazenagem e distribuição de produtos refrigerados, localizadas em São Paulo (capital), Brasília e Campos de Holambra (município de Paranapanema - estado de São Paulo).

Hoje, a Cooperativa congrega 73 cooperados, concentrados nos estados de Minas Gerais, Ceará e São Paulo, totalizando 260 hectares de produção em estufa (cultivo protegido). 
A produção é especializada em flores de corte, contendo rosas, alstroemerias, lisianthus, lírios e outras flores silvestres, além de folhagens, produtos processados (buquês), totalizando mais de 400 variedades em seu portfólio de produção. Flores envasadas são comercializadas, mas a participação nas vendas é baixa.

\section{DIAGNÓSTICO DA OPORTUNIDADE}

\section{A cadeia de valor e a cadeia de suprimentos}

A cadeia de suprimentos da Cooperativa está intimamente ligada ao modelo de negócio da cooperativista. Baseando-se em citação de Konzen e Oliveira (2015), os produtores de flores se organizaram com o objetivo principal da ajuda mútua, em busca de interesses em comum, nos quais o coletivo prevalece sobre o individual.

O produto central de comercialização é a flor cortada, que possui uma durabilidade curta quando comparada a produtos envasados. Faz-se essencial que a comercialização seja efetiva (preço justo e com clientes de boa reputação) e rápida para que não haja quebra devido a não venda dos produtos.

A oferta e a demanda, como em vários mercados de consumo, impactam fortemente a questão da comercialização, e ela é afetada por duas variáveis:

- Variação climática, sendo em um horizonte mais amplo (de seis meses) as temperaturas mínimas durante as diferentes estações e no horizonte mais curto (duas semanas) a "entrada" de frentes frias, que impactam diretamente o ciclo produtivo das plantas.

- Demanda de produtos ao longo ano, que possui características interessantes: datas festivas, como Dia das Mães, Dia dos Namorados e Dia da Mulher; feriados próximos dos finais de semana, que inibem a realização de festas de casamento; meses de férias, quando se têm menor número de festas.

A combinação desses dois movimentos e a área produtiva são os geradores do modelo de oferta e demanda no segmento de flores de corte. Baseada nisso, a Cooperativa desenvolveu um modelo que efetiva a venda antes que o produto seja recebido na unidade central, diminuindo os riscos de perda de vendas e, consequentemente, tendo um alto índice de produtos não faturados. 
A comercialização está baseada em um modelo virtual, acessado via internet, alimentado pelos produtores com suas ofertas diárias para que os clientes cadastrados possam acessar a disponibilidade de flores para efetivar as suas compras.

O modelo é chamado de Sinc (Sistema Integrado Cooperativa A) e pode ser acessado 24 horas por dia ao longo dos sete dias da semana (24 a 7). Atualmente é o maior banco de dados de flores de corte no Brasil, tendo atualizações de volumes disponíveis e seus preços diariamente. Esse modelo foi desenvolvido internamente (in-house), implantado e modelado ao longo dos últimos cinco anos para facilitar a venda de produtos antes da recepção deles na unidade da Cooperativa. O Sinc pode ser acessado por clientes e pela equipe comercial.

A composição comercial é formatada com um gerente e quatro grupos de vendas:

1. Equipe de Vendas ao Varejo (Redes de Varejo Alimentar).

2. Equipe de Vendas aos Decoradores.

3. Equipe de Vendas de Rosas aos Atacadistas.

4. Equipe de Vendas de Flores Silvestres aos Atacadistas.
As equipes de vendas aos atacadistas possuem um coordenador de produtos que define diariamente os preços de venda aos clientes, sempre se baseando na previsão de produção e na demanda de mercado.

Concomitantemente à precificação de flores, os produtores estão inserindo seus produtos diariamente. O ponto importante é que, apesar de sempre o atacadista/ cliente ter a decisão final sobre de qual produtor irá realizar a aquisição, existe um conflito sobre a atuação da equipe comercial. Ela pode ser definida pela racionalidade limitada dos cooperados, que, desconhecendo todos os dados de cada negociação, possuem a percepção de que possa haver negociações oportunistas e perda de vendas por direcionamento inadequado e/ou má gestão comercial.

Também se aplica aqui a assimetria de informações (relativas ao mercado comprador) entre os produtores que estão em suas fazendas e a equipe comercial. Durante os últimos dois anos, a Cooperativa vem reduzindo essas percepções por meio de melhorias e disponibilidades de novos relatórios aos seus cooperados. 


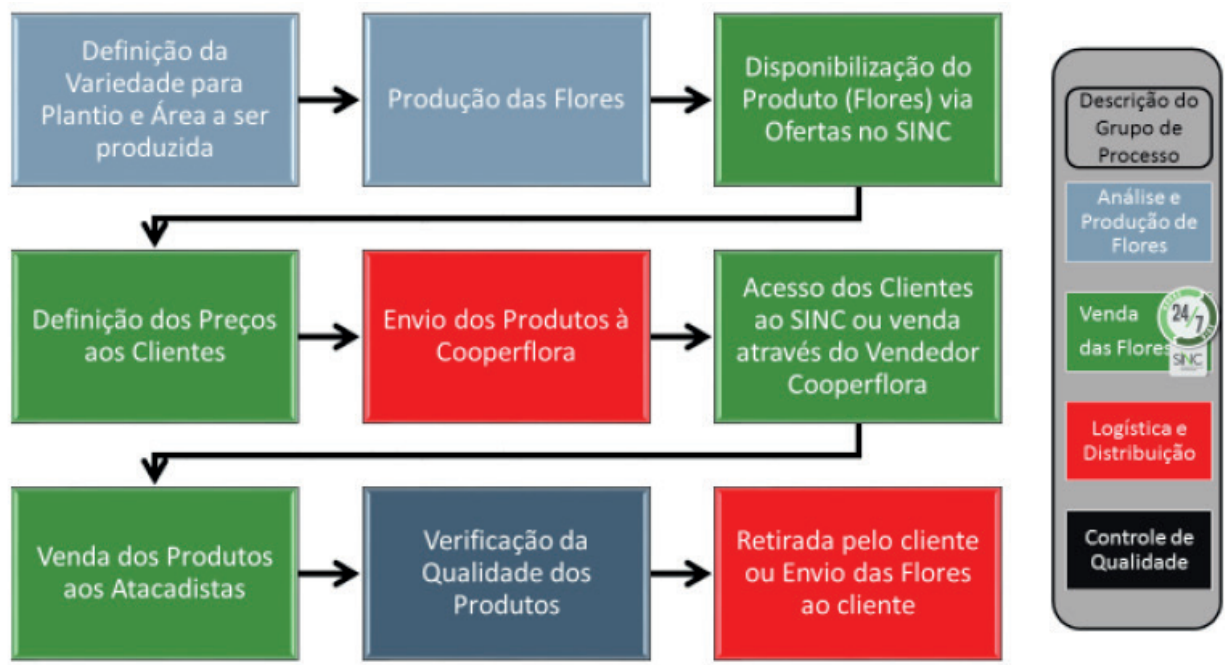

Figura 1 - Cadeia de valor da Cooperativa

Fonte: Elaborado pelos autores, com base na empresa-caso.

A cadeia de valor da Cooperativa inicia pela definição da espécie e variedade de flor a ser plantada (definição cogerida com a equipe Cooperativa). Após a definição, o produtor realizará a aquisição da semente, muda ou estaca para o plantio efetivo. Após a colheita, o produtor embala e prepara o produto para o envio à Unidade da Cooperativa.

$\mathrm{Na}$ Cooperativa os produtos podem ser expedidos imediatamente, em modelo crossdocking, ou vendidos em até três dias (em média). Se o produto não for vendido durante esse período, será descartado, sendo triturado (e passa a ser classificado como produto não faturado). A venda pode ocorrer para clientes abaixo (Figura 2):

- Atacadistas, que revendem em suas regiões de atuação para: decoradores, que realizam as ornamentações de festas de casamento, de bodas, de aniversários e eventos empresariais, públicos; floriculturas, que realizam as vendas para os consumidores, com maior foco nos presentes e lembranças; garden centers, que são especialistas no segmento de jardinagem e realizam as vendas para consumidores finais, para uso próprio; paisagistas, que oferecem serviços de 
implantação e gestão de jardins em residências, condomínios, empresas e praças.

- Grandes decoradores, que compram volumes superiores a pequenos atacadistas, e por essa razão já realizam as aquisições diretamente das cooperativas. No geral, eles realizam as ornamentações de grandes festas de casamento, bodas, aniversários e eventos empresariais, públicos.
- Varejistas alimentares e não alimentares (redes de petfood e material de construção, por exemplo), que realizam as vendas para os consumidores finais. Esses últimos consomem para utilização própria em suas residências.

Dentro do total de faturamento da Cooperativa, $70 \%$ destinam-se ao segmento de atacado, e desses $70 \%, 40 \%$ destinam-se às floriculturas e $60 \%$, aos decoradores profissionais, razão pela qual a importância de criar valor para esses clientes é tão fundamental.

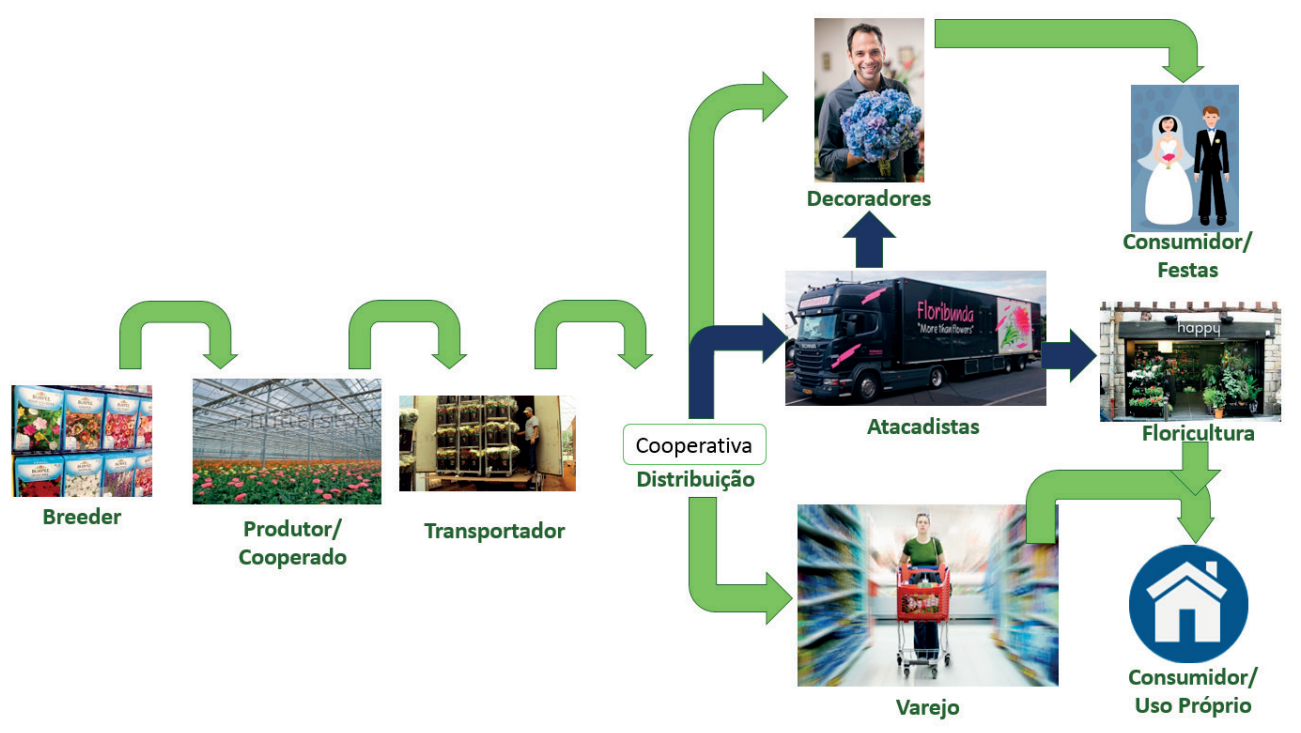

FIGURA 2 - Cadeia de valor da Cooperativa

Fonte: Elaborado pelos autores, com base na empresa-caso. 
PROPOSTA DE CRIAÇÃO DE VALOR

A proposta de valor será baseada na lógica serviço-dominante, entendida que por trás de todo e qualquer bem físico existe a prestação de um serviço relacionado, sendo esse o que dá o real valor àquele bem físico, no caso, as flores.

Segundo Troccoli (2009), pouco se sabe a respeito de quais fatores passados $\mathrm{e}$ presentes são cruciais para a forma como o valor é criado conjuntamente pelas partes comprador e vendedor ao longo do tempo. E a prática de mercado ainda se baseia na teoria econômica que promulga ser arriscada a cooperação. Entretanto, a interdependência é vista pelo autor como um recurso que pode se transformar em cocriação de valor (TROCCOLI, 2009).

O problema a ser resolvido é dado por decoradores localizados no Brasil inteiro, que recebem cotações de festas com antecedência mínima de três meses (sabendo que antes da crise brasileira iniciada em 2014 esses prazos eram no mínimo de seis meses) e, por vezes, com um ano de antecedência.

Entretanto, devido a fatores climáticos e assimetria de informações, a especulação de preços é grande e dificilmente se terá o preço justo por parte do seu atacadista (fornecedor). Isso ocorre devido ao mecanismo de defesa do fornecedor quanto à sua aquisição das flores requeridas pelo decorador.

O resultado final é que tamanha especulação transformou o mercado, ao longo dos últimos dez anos, e atualmente os decoradores realizam as suas compras praticamente na semana da festa.

Pode-se aplicar, nesse caso, a teoria da racionalidade limitada, posto que o decorador possui o comportamento otimizado, entretanto não consegue satisfazer tal desejo devido à falta de informações do mercado futuro. $\mathrm{O}$ fator gera então comportamentos oportunistas, partindo do princípio de que o jogo passa a ser não cooperativo, no qual a informação que um agente possa ter sobre a realidade não está acessível ao outro agente (ZYLBERSTAJN, 1995). 


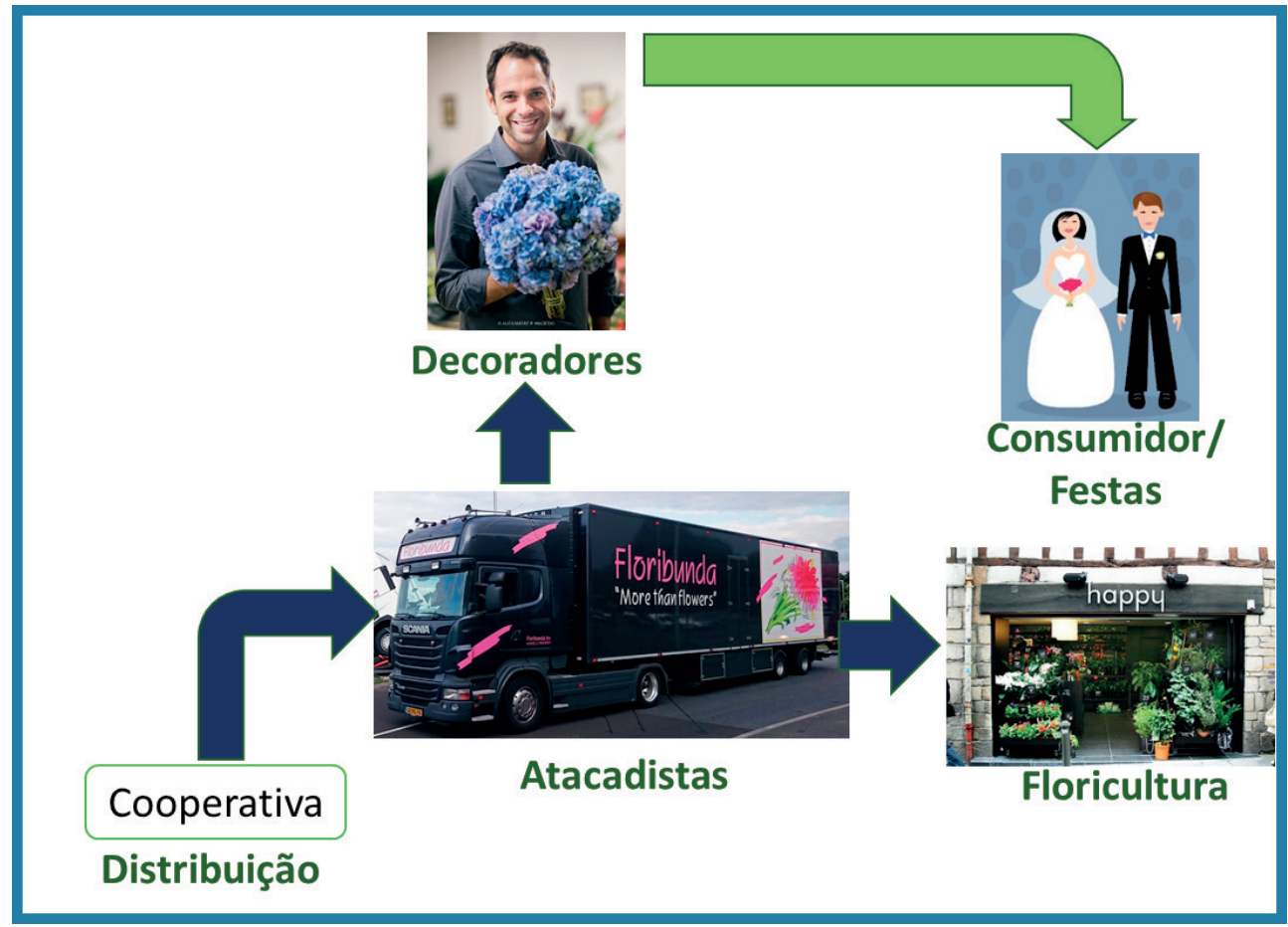

FIGURA 3 - Cadeia em que se propõe a criação de cadeia de valor Fonte: Elaborado pelos autores, com base na empresa-caso.

A proposta de valor é propiciar aos decoradores a oportunidade de terem acesso aos preços antecipadamente (Figura 3), para a elaboração das cotações de suas festas diretamente no Sinc, via acesso on-line, por conexão através dos dados de seu atacadista. Assim, a tela de acesso será a mesma, mas os preços visualizados pelos decoradores estarão adicionados das margens já pré-formatadas pelos atacadistas.
Segundo o conceito de Troccoli (2009), a proposta é maximizar o retorno sobre as vendas de flores, por meio das relações com os decoradores e atacadistas, criando interação na cadeia e valor conjuntamente. Dessa forma, cada um dos três elos envolvidos, quais sejam Produtor, Atacadista e Decorador, realiza o melhor proveito de seus próprios recursos, dos recursos da outra parte e dos recursos em 
conjunto. A proposta é de que o resultante dessa relação se dará pela questão de quão bem cada agente usará os recursos dominados pelo outro agente.

As vantagens esperadas são:

- Criação da alternativa para efetivar a compra antecipadamente, com todos os preços já fixados para os próximos 12 meses (ano móvel).

- Possibilitar a garantia do produto e da qualidade para o decorador e seu cliente final.

- Facilitar a elaboração da cotação aos decoradores, criando melhor visibilidade para o custeio total das festas.

- Possibilitar uma comparação on-line entre as diferentes espécies e variedades de flores, de disponibilidade e preços. Isso ajudará na definição dos produtos que poderão ser utilizados nas festas.

- O decorador poderá eleger o produtor que desejar, o que implicará maior transparência na cadeia como um todo, pois estará dando o poder de decisão diretamente para o maior interessado, o decorador.

\section{CONSIDERAÇÕES FINAIS}

No atual cenário brasileiro, faz-se importante buscar alternativas de redução da assimetria de informações e comportamentos oportunistas, gerando maior informação ao longo da cadeia de fluxo de produtos e seus participantes.

Durante o processo de implantação será de suma importância o entendimento, por parte dos atacadistas, de que essa agregação de valor na cadeia não irá prejudicá-los. Para isso, serão feitas ações de esclarecimento durante o processo e vários pilotos junto aos atacadistas mais estruturados e abertos às inovações.

Será necessário um processo bem estruturado de comunicação e transparência para mitigar eventuais constrangimentos àqueles para os quais a política de preço e atendimento continuará igual, afinal, não se quer perder esses clientes, não obstante os volumes de compra que praticam.

Essa, talvez, seja a questão mais delicada e difícil de gerenciar. Por essa razão, conta-se com o relacionamento de vários anos 
com esses clientes e com a certeza de que, a despeito de sua penetração no faturamento da empresa, o atendimento a eles continuará sendo um item de excelência, por outros meios além dessa nova forma de processo.

\section{CREATING VALUE IN THE CUT FLOWERS CHAIN IN THE} BRAZILIAN MARKET

\section{ABSTRACT}

The objective of this work is to report the proposal of a improvement in a business model, involving the customer service of a cut flowers cooperative, related to an opportunity identified through the detailed analysis of the value chain in which the company is working in the time. A number of key elements were considered for the analysis in question. Based on the premise that the product is highly perishable, production is affected by the climate and its seasonality, the commercialization is using a system of sales through Internet, and the sale is daily, we sought a solution that generates value based in the service-dominant logic, in the case of cut flowers. The model proposed here, already in the beginning of execution, has in its core an opportunity aimed at facilitating the purchase by the last link of the productive chain, the decorator, taking into account that such a model is based on the fact that the resulting of this rela- tionship (firm-decorator) will be successful depending strongly on how well each agent will use the resources dominated by the other agent, in an unequivocal interdependence relationship.

\section{KEYWORDS}

Value creation. B2B market segment. Flower market. Value chain.

\section{REFERÊNCIAS}

INSTITUTO BRASILEIRO DE FLORICULTURA - IBRAFLOR. Reporte anual, 2013. Mercado Interno 12.2014. Holambra: Ibraflor, 2015. Disponível em: <http://ibraflor.com/ns_mer_interno.php $>$. Acesso em: out. 2015.

KONZEN, R. R. P.; OLIVEIRA, C. A. Intercooperação entre cooperativas: barreiras e desafios a serem superados. Revista de Gestão e Organizações Cooperativas - RGC, Santa Maria, v. 2, n. 4, p. 45-48, jul./dez. 2015.

MARCONDES, R. C.; MIGUEL, L. A. P.; FRANKLIN, M. A.; PEREZ, G. Metodologia para elaboração de trabalhos práticos e aplicados: administração e contabilidade. 2017. Disponível em: <http://up. mackenzie.br/stricto-sensu/administracao-do-desenvolvimento-de-negocios-profissional/>. Acesso em: 6 dez. 2017. 
NEVES, M. F.; PINTO, M. J. A. (Org.). Mapeamento e quantificação da cadeia de flores e plantas ornamentais do Brasil. São Paulo, Ocesp, 2015.

SERVIÇO BRASILEIRO DE APOIO ÀS MICRO E PEQUENAS EMPRESAS - SEBRAE. Flores e plantas ornamentais do Brasil: volume 1 - O mercado brasileiro de flores e plantas ornamentais. 2015. Disponível em: <http://www.bibliotecas. sebrae.com.br/chronus/ARQUIVOS_ CHRONUS/bds/bds.nsf/7ed114f4eace9ea970dadf63bc8baa29/\$File/5518.pdf>. Acesso em: nov. 2015.

SILVA, A. A.; BRITO, E. P. Z. Incerteza, racionalidade limitada e comportamento oportunista: um estudo na indústria brasileira. RAM, Rev. Adm. Mackenzie, São Paulo, v. 14, n. 1, p. 176-201, jan./fev. 2013.

TROCCOLI, I. R. Cocriação de valor e fidelização dos clientes: uma visão integrada. Revista Científica Internacional, ano 2, n. 4, p. 1-26, jan. 2009.

TSUBOI, N.; TSURUSHIMA, H. Introdução à história da indústria de flores e plantas ornamentais no Brasil. São Paulo: Lip Gráfica, 2009.
ZYLBERSZTAJN, D. Estruturas de governança e coordenação do agribusiness: uma aplicação da nova economia das instituições. 1995. Tese (Livre docência em Administração) - Faculdade de Economia, Administração e Contabilidade, Universidade de São Paulo, São Paulo, 1995. 